\title{
SOLVENT EXTRACTION OF MOLYBDENUM FROM HYDROCHLORIC ACID SOLUTIONS WITH TRI-OCTYL PHOSPHINE OXIDE: COMPARISON BETWEEN CONVENTIONAL AND MICROWAVE-ASSISTED EXTRACTION TECHNIQUES
}

\author{
Ahmed Boucherit and Hussein Khalaf \\ Laboratory of Chemical Engineering - Faculty of Technology -University of Blida 1, \\ B.P. 270, Blida 09000, Algeria)
}

(Received March 2020 - Accepted June 2020)

\begin{abstract}
Boucherit, A., \& Khalaf, H. (2020). Solvent extraction of molybdenum from hydrochloric acid solutions with tri-octyl phosphine oxide: comparison between conventional and microwave-assisted extraction techniques. Lebanese Science Journal, 21(1), 65-79.

In this paper, the solvent extraction of molybdenum from 0.01-1 $M$ aqueous hydrochloric acid using tri-octyl phosphine oxide (TOPO) as solvent diluted with nhexane has been investigated. The extraction efficiencies of TOPO in the extraction of molybdenum were carried out using conventional extraction and microwave-assisted extraction (MAE) techniques. Molybdenum extraction efficiency was determined by varying separately the different parameters affecting the extraction process including agitation time, hydrochloric acid concentration, solvent concentration (in the organic phase), as well as the irradiation time and microwave power. The MAE technique greatly enhanced the solvent extraction of molybdenum where high extraction percentages were obtained under favorable conditions. In some cases, the percentages extraction of molybdenum obtained with two methods were comparable. The use of MAE technique also showed obvious advantages in terms of a drastic reduction of the extraction time as it was shortened from 15 min to $10 \mathrm{~s}$ in comparison with conventional solvent extraction method.
\end{abstract}

Keywords: Molybdenum, solvent extraction, TOPO, microwave.

\section{INTRODUCTION}

Solvent extraction is an important process largely used in many industrial processes especially for the recovery, selective separation and purification of a variety of metal ions from different aqueous media (Park et al., 2006; Ivam Jr. et al., 2008; Zeng \& Cheng, 2009; Wang et al., 2009; Boucherit et al., 2012; Imam \& El-Nadi, 2018; Li et al., 2019a, 2019b). Unfortunately, this method presents some limitations as it needs the use of organic solvents, equilibrium is not attained only for a long time and presents the formation of emulsions, etc. (Gharehbaghi and Shemirani, 2011; Boucherit et al., 2012). 
In last decades, microwave-assisted extraction (MAE) has been successfully applied in organic synthesis (Thompson and Doraiswamy, 1999; Bonrath, 2004; Remya and Lin, 2011). The main advantages of this technique are the large reduction in extraction times, the higher yield of the extraction and the improved selectivity. In the area of extractive metallurgy this non-conventional technique has shown some advantages as it significantly improves the extraction kinetics and enhances extraction rate of metals from various matrices (Xia \& Pickles, 1997; Cid et al., 2001; Relić et al., 2013; Huang et al., 2016; Tian et al., 2019; Cyganowski et al., 2019; Behera et al., 2019). These techniques were used in the present study to extract molybdenum as it is a metal necessary for both human body, animal and plant (Holzinger et al., 1998; LópezGarcía et al., 2007; Díez-Ortiz et al., 2010; Van Gestel et al., 2011; Li et al., 2019a, 2019b). In recent years, molybdenum has found extensive industrial applications in many technological fields (Saberyan et al., 2003; Park et al., 2006; Zeng and Cheng, 2009; Morreale et al., 2012; Li et al., 2019a, 2019b). The presence of this metal in the environment has encouraged many researchers to extract it by using solvent extraction technique. Many researchers used different solvating agents (TBP, D2EHPA, amines, etc.) to extract molybdenum from different acidic solutions (Yamashoji et al., 1986; Sato et al., 1990; Basualto et al., 2003; Ivam Jr.et al., 2008; Wang et al., 2009; Pathak et al., 2010; Boucherit et al., 2012; Banda et al., 2012; Wu et al., 2012, Ghadiri et al., 2014; Nguyen and Lee, 2015; Mahandra et al., 2018 ; Zeid et al., 2018; Imam and ElNadi, 2018; Yacouba et al., 2019; Li et al., 2019a, 2019b). Researchers extracted molybdenum from aqueous acid solutions by tri-octyl phosphine oxide (TOPO) and determined different molybdenum complexes at low and high acidities (Yamashoji et al., 1986; Sato et al., 1990; Basualto et al., 2003; Chaibou Yacouba et al., 2019). Band et al. (2012) have investigated the separation and recovery of molybdenum from the synthetic chloride leach liquors by employing TOPO. The literature survey reveals that the determination of trace amount of molybdenum in various media was carried out by several analytical techniques. These methods include spectrophotometry and inductively coupled plasma atomic emission spectrometry and atomic emission spectrometry (Filik et al., 2004; Boucherit et al., 2012; Ghadiri et al., 2014; Nguyen and Lee, 2015; Imam and El-Nadi 2018; Mahandra et al., 2018; Zeid et al., 2018; Chaibou Yacouba et al., 2019; Li et al., 2019a, 2019b).

The literature survey showed that there is no comprehensive information on the effects of microwave irradiations on the solvent extraction of molybdenum with TOPO from 0.01-1 $\mathrm{M}$ aqueous hydrochloric acid solutions. As an extension of our studies on molybdenum extraction (Boucherit et al., 2012) the main aim of this research was to evaluate the suitability of MAE method as compared to conventional solvent extraction method for the extraction of molybdenum from diluted hydrochloric acid solutions with TOPO. In this work, parameters including agitation time, initial hydrochloric acid concentration, and solvent concentration were investigated. Further, parameters influencing microwave-assisted extraction such as irradiation time and microwave power were fully investigated in order to obtain suitable conditions for effective solvent extraction of molybdenum. 


\section{Experimental}

\section{Reagents and solutions}

The molybdenum salt, ammonium molybdate 4-hydrate $\left(\mathrm{Mo}_{7} \mathrm{O}_{24}\left(\mathrm{NH}_{4}\right)_{6} .4 \mathrm{H}_{2} \mathrm{O}\right)$ with a purity of $99 \%(\mathrm{w} / \mathrm{w})$ was supplied from Panreac Quimica. The solvent reagent used in this work was tri-n-octy1 phosphine oxide (TOPO, industrial grade, $97 \%(\mathrm{w} / \mathrm{w})$ purity, Fluka) and was used as received. Hydrochloric acid $(\mathrm{HCl}), 37 \%(\mathrm{w} / \mathrm{w})$ was obtained from Sigma-Aldrich. The commercial hexane (95\%, Biochem Chemopharma) was employed as diluent in order to prepare the organic phase.

A stock solution of molybdenum was prepared by dissolving $0.1856 \mathrm{~g}$ of molybdenum salt in distilled water to obtain Mo(VI) concentration of $1000 \mathrm{mg} / \mathrm{L}$. The initial concentration of molybdenum in the aqueous phases in all experiments were $10^{-4}$ $\mathrm{M}$ and $10^{-2} \mathrm{M}$ and were obtained by diluting stock molybdenum solutions and the addition of predetermined amount of $\mathrm{HCl}$ solution into distilled water. The organic phase was prepared by mixing TOPO with n-hexane at a definite concentration.

\section{Extraction techniques}

Two extractions techniques (conventional extraction, microwave-assisted extraction (MAE)) were used and compared.

\section{Conventional extraction}

In this work, conventional extraction of molybdenum was carried out in $125-\mathrm{mL}$ separatory funnels containing aqueous and organic phases under selected experimental conditions. The two phases were stirred with a mechanical shaker (Promax 1020, Heidolph Instruments, Schwabach, Germany) at 9 rpm stirring speed (Boucherit et al., 2012). This speed ensured a perfect agitation of the mixture. Then the separating funnels were allowed to stay for $10 \mathrm{~min}$ and the aqueous and organic phases were separated. Aqueous phases were stocked for their further analysis.

\section{Microwave-assisted Extraction}

The microwave-assisted extraction (MAE) was carried out in an experimental microwave oven (MARS-S, CEM Corporate Matthews, NC, USA) with a microwave power of $1600 \mathrm{~W}$ and the frequency was set on $2.45 \mathrm{GHz}$. The apparatus employed is equipped with eight extraction vessels made of PTFE. The microwave oven is equipped with a temperature monitor as well as a microprocessor programmer software to control the performance parameters of the microwave device, i.e., microwave power, temperature and running time. An inboard temperature control system is used for the control of temperature inside the extraction vessels. The temperature which was set at $26{ }^{\circ} \mathrm{C}$ was measured by an infrared sensor incorporated solely in a control vessel and the pressure was maintained at 15 PSI throughout the experiments. 


\section{Analytical technique}

For the two investigated extractions methods (conventional extraction, MAE), after the settling and separation of the two phases, the molybdenum concentration in the aqueous phase (raffinate) was determined by Inductively Coupled Plasma Atomic Emission Spectrometry (ICP-AES) (model Optima 4300 DV Perkin Elmer, Uberlingen, Germany) at a wavelength of $202.031 \mathrm{~nm}$ after diluting the aqueous samples appropriately. The concentration of the molybdenum ions in the organic phase was determined through the mass balance. The operational instrumental parameters of the ICP-AES equipment are given in Table 1.

Table 1. Instrumentation and operating conditions for ICP-AES.

\begin{tabular}{|l|c|}
\hline Wavelength, $\mathrm{nm}$ & 202.031 \\
\hline RF power, $\mathrm{kW}$ & 1.45 \\
\hline Integration time, $\mathrm{ms}$ & 100 \\
\hline Liquid flow rate, $\mathrm{mL} / \mathrm{min}$ & 0.05 \\
\hline Outer gas flow rate, $\mathrm{L} / \mathrm{min}$ & 15 \\
\hline Intermediate gas flow rate, $\mathrm{L} / \mathrm{min}$ & 0.5 \\
\hline Central gas flowrate, $\mathrm{L} / \mathrm{min}$ & 0.7 \\
\hline Viewing height above load coil, $\mathrm{mm}$ & 5 \\
\hline Injector tube inner diameter, $\mathrm{mm}$ & 2 \\
\hline
\end{tabular}

The molybdenum solvent extraction performance was quantified through the percentage $\mathrm{Mo}(\mathrm{VI})$ extraction (E, \%) according to the relation:

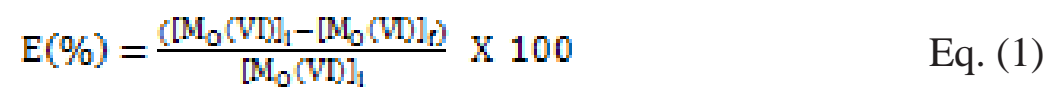

where $[\mathrm{Mo}(\mathrm{VI})]_{\mathrm{i}}$ and $[\mathrm{Mo}(\mathrm{VI})]_{\mathrm{f}}$ are respectively the initial and final molybdenum concentrations.

All the experiments were carried out at with equal volume of aqueous and organic phase $(10 \mathrm{~mL})$ and at $26{ }^{\circ} \mathrm{C}$ in triplicate and the mean values of extraction percentages of molybdenum and standard deviations were calculated. Phase separation after extraction was very fast and good and no formation of emulsions was observed. The relative standard deviation values did not exceed 3\% and this show the validity and good precisions of the data represented in the figures. The mass balance for all the experiments was found to be within $\pm 5 \%$.

\section{RESULTS AND DISCUSSION}

The effects of agitation time, hydrochloric acid concentration, and TOPO concentration, under conventional extraction, irradiation time and microwave power under microwave-assisted extraction were studied. The conditions for maximum percentage extraction of molybdenum were determined for both investigated extraction method. 


\section{Kinetic of molybdenum extraction}

The solvent extraction is known as an equilibrium process and the knowledge of agitation time necessary to reach equilibrium is very important as it influences the extraction process. The influence of agitation time on the extraction efficiency of molybdenum from aqueous acidic solutions was investigated under conventional extraction and under microwave-assisted extraction. With a view to obtain the optimal agitation time, the studies of the kinetics of the Mo(VI) extraction were carried out by shaking aqueous phases of $10^{-2} \mathrm{M}$ and $10^{-4} \mathrm{M} \mathrm{Mo}(\mathrm{VI})$ dissolved in $0.01 \mathrm{M}$ and $1 \mathrm{M} \mathrm{HCl}$ solutions and an organic phase consisting of $0.02 \mathrm{M}$ TOPO diluted with n-hexane for different agitation times intervals varying from 2 to $25 \mathrm{~min}$ under conventional extraction and for various lengths of microwave irradiation time varying from 3 to $15 \mathrm{~s}$.

\section{Kinetic of the molybdenum conventional extraction}

Figures 1 and 2 compare the percentages $\mathrm{Mo}(\mathrm{VI})$ extraction conducted from molybdenum solution with concentrations of $10^{-4} \mathrm{M}$ and $10^{-2} \mathrm{M}$ dissolved in $0.01 \mathrm{M}$ and $1 \mathrm{M} \mathrm{HCl}$ solutions respectively for different agitation times (2-25 min) under conventional extraction. These figures show that the percentage Mo(VI) extraction increases with agitation time till reaching a plateau where the respective percentage Mo(VI) extraction attains a constant value. The data in the figure 1 indicate that an agitation time of $15 \mathrm{~min}$ is good enough to reach the extraction equilibrium and where constant values of the percentages $\mathrm{Mo}(\mathrm{VI})$ extraction of $55 \%$ and $35 \%$ were obtained for the extractions conducted from aqueous phases of $10^{-2} \mathrm{M}$ and $10^{-4} \mathrm{M} \mathrm{Mo}$ (VI) respectively dissolved in $0.01 \mathrm{M} \mathrm{HCl}$ solution. The figure 2 shows that extraction equilibrium was attained also after 15 min of contact between phases and maximum percentages $\mathrm{Mo}(\mathrm{VI})$ extraction of $75 \%$ and $69 \%$ were achieved for extractions conducted from aqueous phases of $10^{-2} \mathrm{M}$ and $10^{-4} \mathrm{M} \mathrm{Mo}(\mathrm{VI})$ respectively dissolved in $1 \mathrm{M} \mathrm{HCl}$ solution. As shown in figures 1 and 2, experiments conducted for agitation time interval (15-25 min) did not affect the percentage Mo(VI) extraction significantly. In order to ensure the maximum percentage Mo(VI) extraction, an agitation time of 15 min was chosen for the subsequent extraction studies.

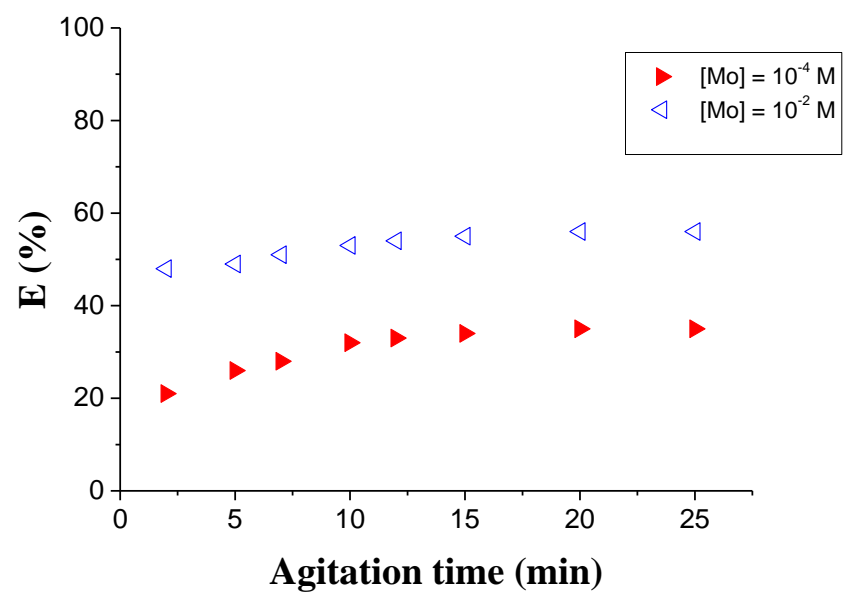

Figure 1. Percentage molybdenum extraction versus agitation time, $[\mathrm{HCl}]=0.01 \mathrm{M},[\mathrm{TOPO}]=0.02 \mathrm{M}, \mathrm{V}_{\mathrm{aqu}} / \mathrm{V}_{\text {org }}=1, \mathrm{~T}=26^{\circ} \mathrm{C}$. 


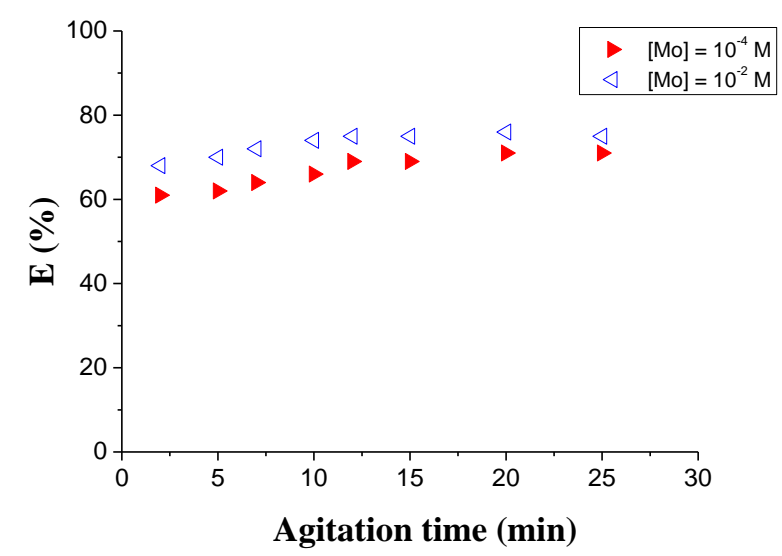

Figure 2. Percentage molybdenum extraction versus agitation time, $[\mathrm{HCl}]=1 \mathrm{M},[\mathrm{TOPO}]=0.02 \mathrm{M}, \mathrm{V}_{\text {aqu}} / \mathrm{V}_{\text {org }}=1, \mathrm{~T}=26^{\circ} \mathrm{C}$.

\section{Kinetic of the molybdenum extraction under microwave}

The influence of microwave irradiation time on Mo(VI) solution with concentrations of $10^{-4} \mathrm{M}$ and $10^{-2} \mathrm{M}$ dissolved in $0.01 \mathrm{M}$ and $1 \mathrm{M} \mathrm{HCl}$ solutions have been carried out at $20 \mathrm{~W}$ microwave power for different irradiations times (3-15 s). As showed in figure 3, the maximal percentages $\mathrm{Mo}(\mathrm{VI})$ extractions of $75 \%$ and $68 \%$ were obtained for only $10 \mathrm{~s}$ microwave irradiation time for aqueous phases of $10^{-2} \mathrm{M}$ and $10^{-4}$ $\mathrm{M} \mathrm{Mo(VI)} \mathrm{dissolved} \mathrm{respectively} \mathrm{in} 0.01 \mathrm{M} \mathrm{HCl}$, the longer irradiation time did not result in further increase of $\mathrm{Mo}(\mathrm{VI})$ extraction. The results presented in figure 4 show that the percentage $\mathrm{Mo}(\mathrm{VI})$ extraction reaches $92 \%$ and $82 \%$ within $10 \mathrm{~s}$ microwave irradiation time for extractions conducted from aqueous phases of $10^{-2} \mathrm{M}$ and $10^{-4} \mathrm{M}$ $\mathrm{Mo}(\mathrm{VI})$ respectively dissolved in $1 \mathrm{M} \mathrm{HCl}$ solution. Figures 3 and 4 show that beyond $10 \mathrm{~s}$, no significant increase in the percentage Mo(VI) extraction was observed. The results indicated, that the kinetics of molybdenum extraction were very fast and that microwave irradiations have enhanced its extraction in a short irradiation time (10 s). Based on these results a microwave irradiation time of about $10 \mathrm{~s}$ was maintained in all the extraction experiments so as to ensure the equilibrium.

\section{Comparison of MAE and conventional extraction methods}

Figures 3 and 4 show clearly that MAE method was the fastest extraction technique compared to conventional extraction method as it can greatly reduce the extraction time for the same operating condition. The equilibrium time was about 90 times shorter when the MAE method was employed as compared to the conventional one. MAE technique also gives higher percentages $\mathrm{Mo}(\mathrm{VI})$ extraction in comparison with those obtained under conventional extraction. In terms of the percentage Mo(VI) extraction, the best results were obtained by MAE technique, which gave the highest percentage $\mathrm{Mo}(\mathrm{VI})$ extraction value $(92 \%)$ for extraction conducted from aqueous phase of $10^{-2} \mathrm{M} \mathrm{Mo}(\mathrm{VI})$ dissolved in $1 \mathrm{M} \mathrm{HCl}$ solution. Due to the considerable savings in time, this extraction method was suitable for fast extraction of molybdenum with TOPO. MAE improves the percentage Mo(VI) extraction in comparison with conventional extraction as it promotes the probability of contact between molybdenum ions and TOPO ligands in solution. 


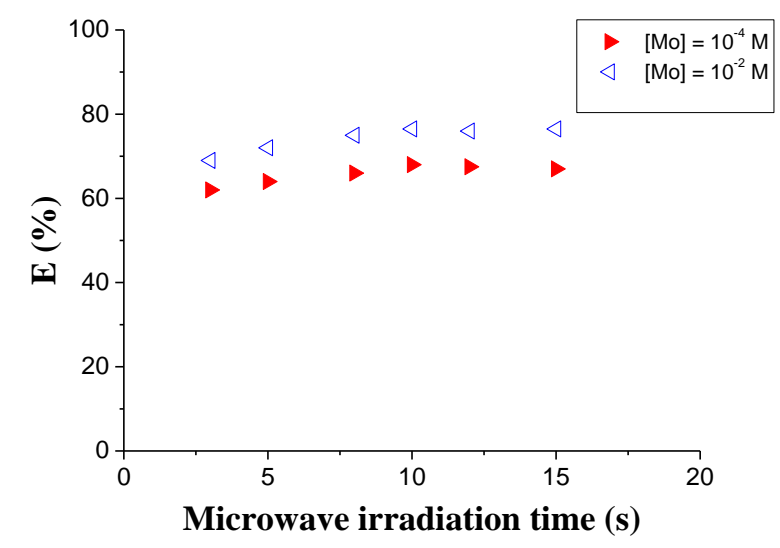

Figure 3. Percentage molybdenum extraction versus microwave irradiation time, $[\mathrm{HCl}]=0.01 \mathrm{M},[\mathrm{TOPO}]=0.02 \mathrm{M}, \mathrm{V}_{\mathrm{aqu}} / \mathrm{V}_{\mathrm{org}}=1, \mathrm{Mw}: \mathrm{P}_{\mathrm{Mw}}=20 \mathrm{~W}, \mathrm{f}_{\mathrm{Mw}}=2.45$, GHz, $\mathrm{T}=26^{\circ} \mathrm{C}$.

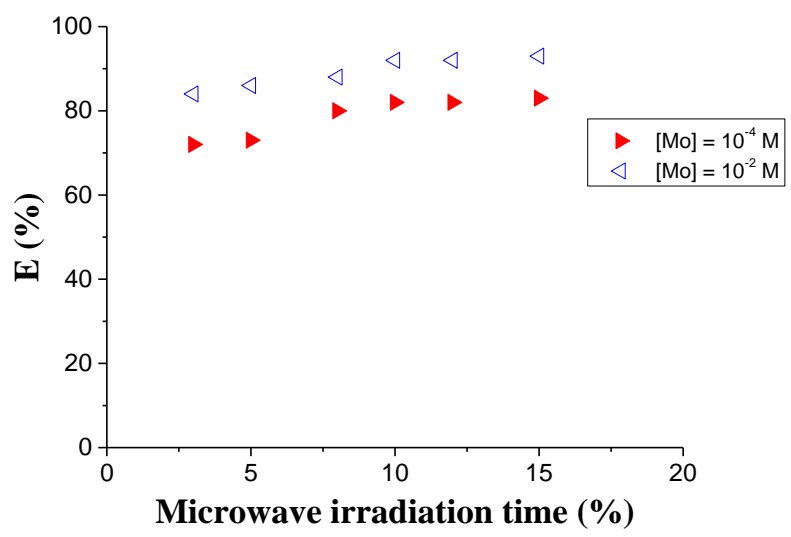

Figure 4. Percentage molybdenum extraction versus microwave irradiation time, $[\mathrm{HCl}]=1 \mathrm{M},[\mathrm{TOPO}]=0.02 \mathrm{M}, \mathrm{V}_{\mathrm{aqu}} / \mathrm{V}_{\text {org }}=1, \mathrm{Mw}: \mathrm{P}_{\mathrm{Mw}}=20 \mathrm{~W}, \mathrm{f}_{\mathrm{Mw}}=2.45 \mathrm{GHz}$, $\mathbf{T}=26^{\circ} \mathrm{C}$.

\section{Effect of HCl concentration}

The effect of $\mathrm{HCl}$ concentration on the percentage $\mathrm{Mo}(\mathrm{VI})$ extraction from molybdenum solution with concentrations of $10^{-4} \mathrm{M}$ and $10^{-2} \mathrm{M}$ by $0.02 \mathrm{M}$ TOPO solution diluted with $\mathrm{n}$-hexane was investigated in the $\mathrm{HCl}$ concentration range 0.01-1 $\mathrm{M}$ under conventional extraction and microwave-assisted extraction methods. The obtained results (Figures 5 and 6), show an increase in the percentage Mo(VI) extraction with $\mathrm{HCl}$ concentration.

Figure 5 shows that for extractions conducted from aqueous phases of $10^{-2} \mathrm{M}$ $\mathrm{Mo}(\mathrm{VI})$, when the $\mathrm{HCl}$ concentration was increased from 0.01 to $1 \mathrm{M}$, the percentage Mo(VI) extraction increased from 59.6 to $75.4 \%$ under conventional extraction and from 84.2 to $94.8 \%$ under microwave-assisted extraction. Whereas figure 6 shows that for molybdenum extraction conducted from aqueous phases of $10^{-4} \mathrm{M} \mathrm{Mo}(\mathrm{VI})$ the percentage $\mathrm{Mo}(\mathrm{VI})$ extraction increased from 36.6 to $75.4 \%$ under conventional extraction and from 71.7 to $89.4 \%$ under microwave-assisted extraction, as the $\mathrm{HCl}$ 
concentration increased from 0.01 to $1 \mathrm{M}$, respectively. It is also clear that the percentage Mo(VI) extraction under microwave-assisted extraction is higher than that under conventional extraction particularly for $\mathrm{HCl}$ concentration in the range 0.01-0.4 M.

The comparison of the percentage Mo(VI) extraction with the two extraction methods showed, that for $0.01 \mathrm{M} \mathrm{HCl}$ the percentage Mo(VI) extraction was about $40 \%$ and $96 \%$ higher for the microwave-assisted extraction than for the conventional extraction for extractions conducted from $10^{-2} \mathrm{M}$ and $10^{-4} \mathrm{M}$ Mo (VI) aqueous phases, respectively.

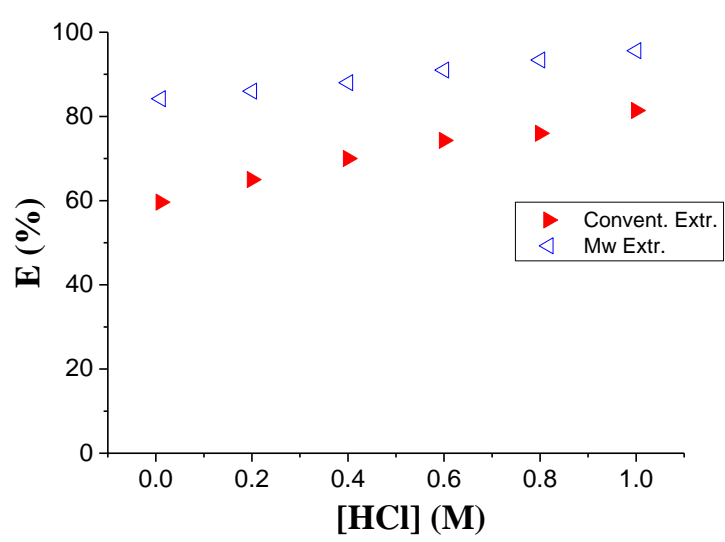

Figure 5. Percentage molybdenum extraction versus hydrochloric acid concentration, $[\mathrm{Mo}]=10^{-2} \mathrm{M},[\mathrm{TOPO}]=0.02 \mathrm{M}, \mathrm{t}_{\text {agit }}=15 \mathrm{~min}, \mathrm{t}_{\text {irrad }}=10 \mathrm{~s}$, $\mathrm{V}_{\text {aqu }} / \mathrm{V}_{\text {org }}=1, \mathrm{~T}=26^{\circ} \mathrm{C}$.

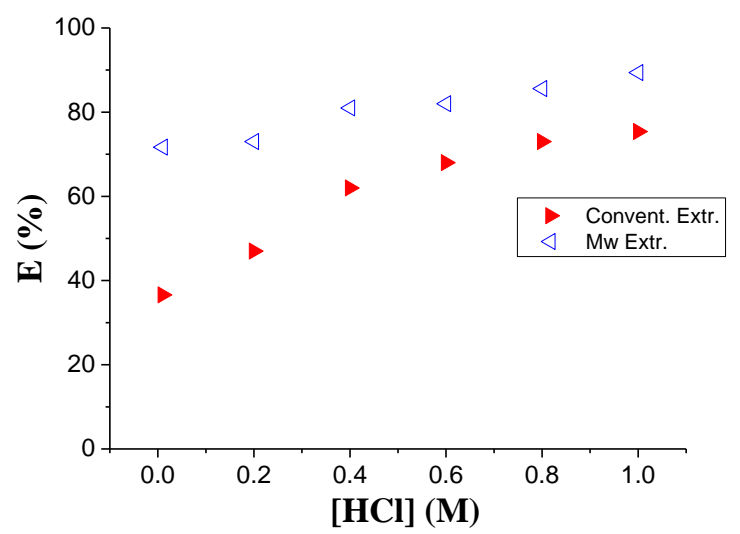

Figure 6. Percentage molybdenum extraction versus hydrochloric acid concentration, $[\mathrm{Mo}]=10^{-4} \mathrm{M},[\mathrm{TOPO}]=0.02 \mathrm{M}, \mathrm{t}_{\text {agit }}=15 \mathrm{~min}, \mathrm{t}_{\text {irrad }}=10 \mathrm{~s}$, $\mathrm{V}_{\text {aqu }} / \mathrm{V}_{\text {org }}=1, \mathrm{~T}=26^{\circ} \mathrm{C}$.

\section{Effect of TOPO concentration}

The effect of TOPO concentration on the extraction of $10^{-4} \mathrm{M}$ and $10^{-2} \mathrm{M}$ $\mathrm{Mo}(\mathrm{VI})$ dissolved in $0.01 \mathrm{M}$ and $1 \mathrm{M} \mathrm{HCl}$ solutions was studied by varying TOPO concentration in the range $0.02-0.1 \mathrm{M}$ under conventional extraction and microwaveassisted extraction methods. The results obtained are represented in figures 7-10. TOPO 
is effective for the extraction of molybdenum and the percentage $\mathrm{Mo}(\mathrm{VI})$ extraction is found higher under microwave-assisted extraction than under conventional extraction.

For extractions conducted from $10^{-2} \mathrm{M} \mathrm{Mo}(\mathrm{VI})$ dissolved in $1 \mathrm{M} \mathrm{HCl}$ solution, the variation of the TOPO concentration from 0.02 to $0.1 \mathrm{M}$ leads to an increase in the percentage $\mathrm{Mo}(\mathrm{VI})$ extraction from $75.4 \%$ at $0.02 \mathrm{M}$ TOPO to $98.9 \%$ at $0.1 \mathrm{M}$ TOPO for conventional extraction (Figure 7). The percentage Mo(VI) extraction only changes slightly (96 to $99.6 \%$ ) with an increase in the TOPO concentration from 0.02 to $0.1 \mathrm{M}$ under microwave-assisted extraction. The two extraction curves coincide for TOPO concentrations greater than $0.06 \mathrm{M}$. The percentage $\mathrm{Mo}(\mathrm{VI})$ extraction was up to about $27 \%$ higher under microwave-assisted extraction than under conventional extraction at $0.02 \mathrm{M}$ TOPO. The microwave-assisted extraction method seems to be more effective for the extraction of molybdenum than the conventional extraction method.

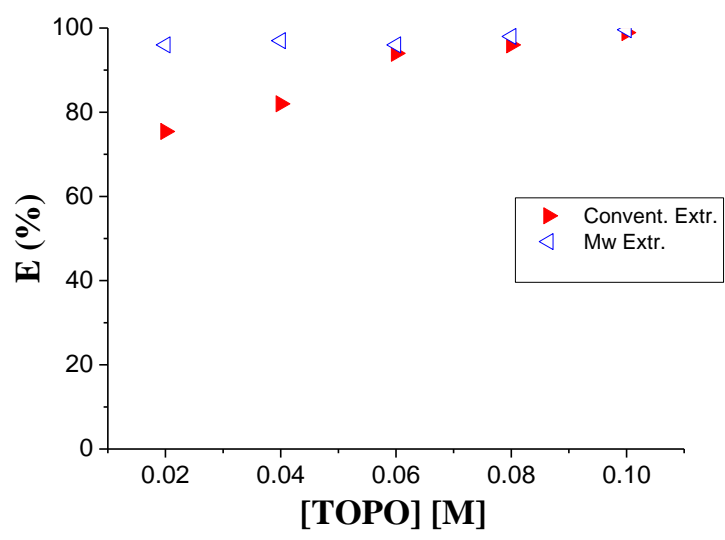

Figure 7. Percentage molybdenum extraction versus TOPO concentration, $[\mathrm{Mo}]=10^{-2} \mathrm{M},[\mathrm{HCl}]=1 \mathrm{M}, \mathrm{t}_{\text {agit }}=15 \mathrm{~min}, \mathrm{t}_{\text {irrad }}=10 \mathrm{~s}, \mathrm{~V}_{\mathrm{aqu}} / \mathrm{V}_{\text {org }}=1, \mathrm{~T}=26^{\circ} \mathrm{C}$.

Figure 8 shows that for extractions conducted from $10^{-4} \mathrm{M} \mathrm{Mo}(\mathrm{VI})$ dissolved in $1 \mathrm{M} \mathrm{HCl}$ solution, the percentage Mo(VI) extraction increased from 73.9 to $99.8 \%$ and from 87.1 to $98 \%$ under conventional extraction and microwave-assisted extraction respectively, when increasing the TOPO concentration from 0.02 to $0.1 \mathrm{M}$.

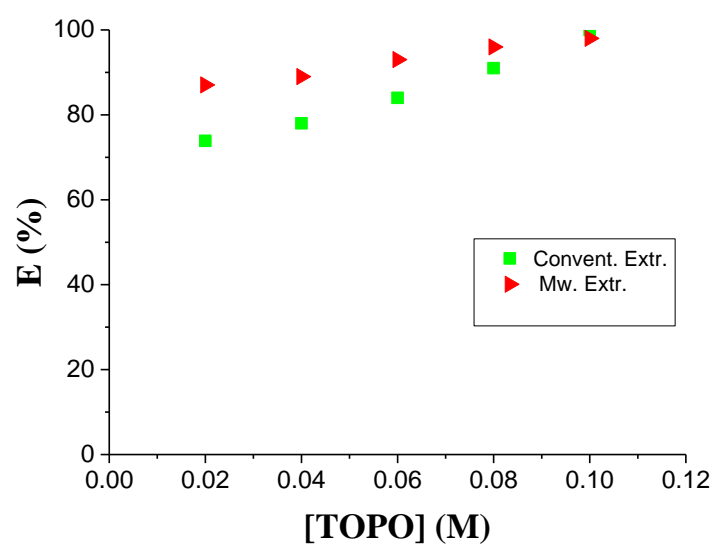

Figure 8. Percentage molybdenum extraction versus TOPO concentration, $[\mathrm{Mo}]=10^{-4} \mathrm{M},[\mathrm{HCl}]=1 \mathrm{M}, \mathrm{t}_{\text {agit }}=15 \mathrm{~min}, \mathrm{t}_{\text {irrad }}=10 \mathrm{~s}, \mathrm{~V}_{\mathrm{aqu}} / \mathrm{V}_{\text {org }}=1, \mathrm{~T}=26{ }^{\circ} \mathrm{C}$. 
The extraction of molybdenum was found quantitative for both methods at $0.1 \mathrm{M}$ TOPO. The percentage $\mathrm{Mo}(\mathrm{VI})$ extraction is higher under microwave-assisted extraction than under the conventional extraction when the concentration of TOPO was in the range $0.02-0.08 \mathrm{M}$. As seen from figure 8 , for $0.02 \mathrm{M}$ TOPO the percentage $\mathrm{Mo}(\mathrm{VI})$ extraction under microwave extraction is high by about $18 \%$ than that under conventional extraction.

For extractions conducted from $10^{-2} \mathrm{M} \mathrm{Mo(VI)}$ dissolved in $0.01 \mathrm{M} \mathrm{HCl}$ solution, the percentage Mo(VI) extraction increased from 59.6 to $97.4 \%$ and from 84.2 to $98.7 \%$ as the TOPO concentration increased from 0.02 to $0.1 \mathrm{M}$ under conventional extraction and under microwave-assisted extraction, respectively (Figure 9). The percentage $\mathrm{Mo}(\mathrm{VI})$ extraction increases rapidly with increasing of TOPO concentration in the range $0.02-0.04 \mathrm{M}$ and becomes constant nearly $98 \%$ for TOPO concentration greater than $0.04 \mathrm{M}$ under microwave -assisted extraction. The two extraction curves coincide for TOPO concentrations greater than $0.06 \mathrm{M}$. Comparing the two extraction techniques the highest percentage $\mathrm{Mo}(\mathrm{VI})$ extraction was nearly $98 \%$ and obtained for both methods at $0.1 \mathrm{M}$ TOPO. The comparison of percentage Mo(VI) extraction with the two extraction methods shows, that the percentage Mo(VI) extraction is higher under MAE than under the conventional extraction when the concentration of TOPO was in the range $0.02-0.06 \mathrm{M}$. It is to note that for $0.02 \mathrm{M}$ TOPO the percentage Mo(VI) extraction was up to about $41 \%$ higher under the microwave-assisted extraction than under the conventional extraction.

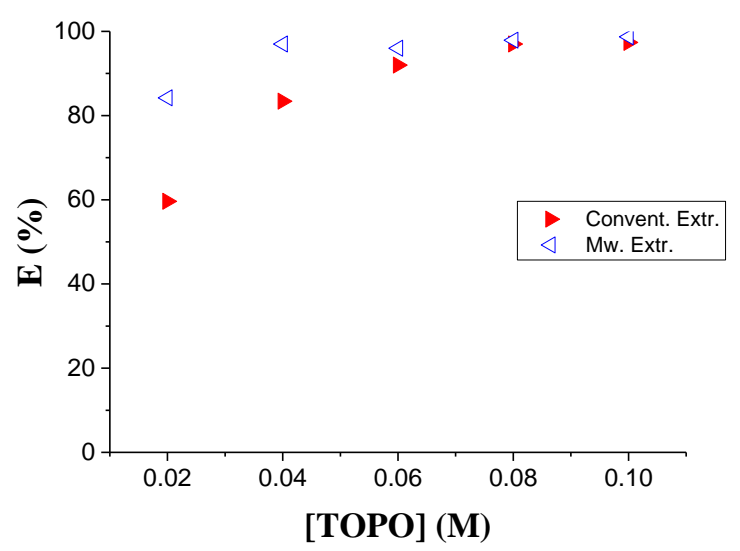

Figure 9. Percentage molybdenum extraction versus TOPO concentration, $[\mathrm{Mo}]=10^{-2} \mathrm{M},[\mathrm{HCl}]=0.01 \mathrm{M}, \mathrm{t}_{\text {agit }}=15 \mathrm{~min}, \mathrm{t}_{\text {irrad }}=10 \mathrm{~s}, \mathrm{~V}_{\text {aqu }} / \mathrm{V}_{\text {org }}=1, \mathrm{~T}=26^{\circ} \mathrm{C}$.

In figure 10 , for extractions conducted from $10^{-4} \mathrm{M} \mathrm{Mo}(\mathrm{VI})$ dissolved in $0.01 \mathrm{M}$ $\mathrm{HCl}$ solution, the variation of the TOPO concentration from 0.02 to $0.1 \mathrm{M}$ leads to an increase in the percentage $\mathrm{Mo}(\mathrm{VI})$ extraction from $36.6 \%$ at $0.02 \mathrm{M}$ TOPO to $44 \%$ at $0.06 \mathrm{M}$ TOPO and from $71.7 \%$ at $0.01 \mathrm{M}$ TOPO to $82 \%$ at $0.06 \mathrm{M}$ TOPO under conventional extraction and under microwave-assisted extraction, respectively. For both extraction techniques the extraction of molybdenum slightly rises with increasing of TOPO concentration beyond $0.06 \mathrm{M}$. The percentage $\mathrm{Mo}(\mathrm{VI})$ extraction reaches $45.3 \%$ and $84.8 \%$ at $0.1 \mathrm{M}$ TOPO under conventional extraction and microwave-assisted extraction, respectively. It can be seen from figure 10 that the microwave-assisted extraction is much better than the conventional extraction. The comparison of percentages $\mathrm{Mo}(\mathrm{VI})$ extraction with the two extraction methods shows, that for $0.02 \mathrm{M}$ 
TOPO the percentage Mo(VI) extraction was up to 2 times higher under the microwaveassisted extraction than under the conventional extraction.

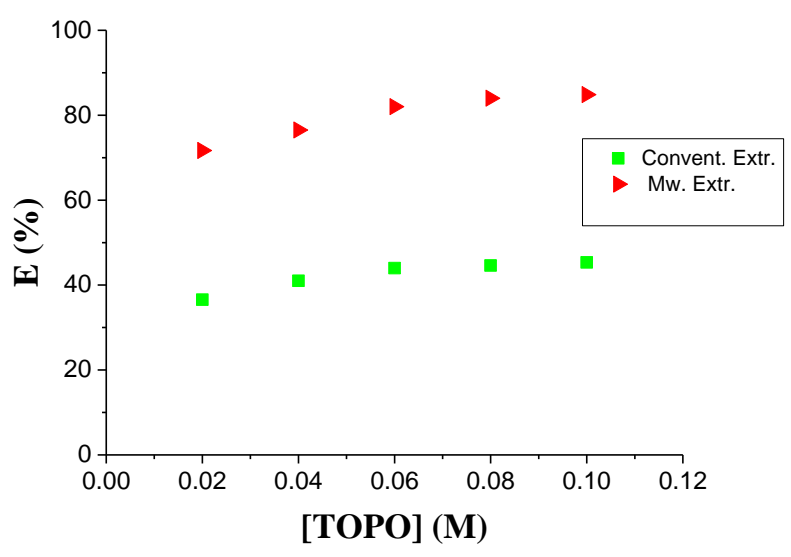

Figure 10. Percentage molybdenum extraction versus hydrochloric acid concentration, $[\mathrm{Mo}]=10^{-4} \mathrm{M},[\mathrm{HCl}]=0.01 \mathrm{M}, \mathrm{t}_{\text {agit }}=15 \mathrm{~min}, \mathrm{t}_{\text {irrad }}=10 \mathrm{~s}$, $\mathrm{V}_{\text {aqu }} / \mathrm{V}_{\text {org }}=1, \mathrm{~T}=26^{\circ} \mathrm{C}$.

\section{Effect of microwave power}

The effect of microwave power on the solvent extraction of molybdenum was studied in the range 20-100 W. Molybdenum solutions with concentrations of $10^{-4} \mathrm{M}$ and $10^{-2} \mathrm{M} \mathrm{Mo}(\mathrm{VI})$ aqueous phases were dissolved in $0.01 \mathrm{M}$ and $1 \mathrm{M} \mathrm{HCl}$ solutions and contacted with an organic phase consisting of $0.02 \mathrm{M}$ TOPO solution diluted with n-hexane. The results illustrated in figures 11 and 12 show that the microwave-assisted extraction of $\mathrm{Mo}(\mathrm{VI})$ conducted from $10^{-2} \mathrm{M} \mathrm{Mo}(\mathrm{VI})$ is higher than that conducted from $10^{-4} \mathrm{M} \mathrm{Mo}(\mathrm{VI})$. The results depicted in figure 11 indicated that microwave power in the studied range 20-100 $\mathrm{W}$ has no significant effect on $\mathrm{Mo}(\mathrm{VI})$ extraction. The means percentages $\mathrm{Mo}(\mathrm{VI})$ extraction values of respectively $73 \%$ and $84 \%$ for $10^{-4} \mathrm{M}$ and $10^{-2}$ M Mo(VI) were obtained.

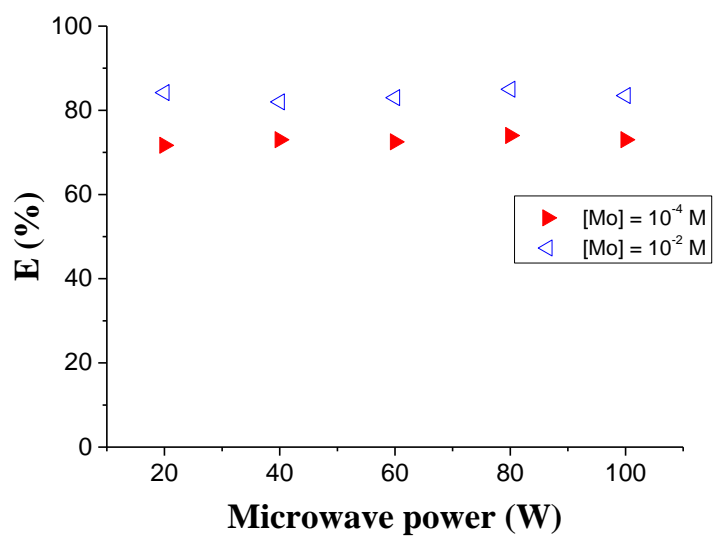

Figure 11. Percentage molybdenum extraction versus microwave power, $[\mathrm{HCl}]=$ $0.01 \mathrm{M},[\mathrm{TOPO}]=0.02 \mathrm{M}, \mathrm{t}_{\text {irrad }}=10 \mathrm{~s}, \mathrm{~V}_{\mathrm{aqu}} / \mathrm{V}_{\text {org }}=1, \mathrm{~T}=26^{\circ} \mathrm{C}$. 
As presented in figure 12, the increase in the microwave power from 20 to 100 W leads to a slight increase in the percentage Mo(VI) extraction from 87 to $96 \%$ for $10^{-4}$ $\mathrm{M} \mathrm{Mo}(\mathrm{VI})$ and from 94 to $98 \%$ for $10^{-2} \mathrm{M} \mathrm{Mo}(\mathrm{VI})$, respectively. The comparison of percentage $\mathrm{Mo}(\mathrm{VI})$ extraction with the two initials molybdenum concentrations of $10^{-4}$ $\mathrm{M}$ and $10^{-2} \mathrm{M} \mathrm{Mo}(\mathrm{VI})$ showed, that for $20 \mathrm{~W}$ the percentage of $\mathrm{Mo}(\mathrm{VI})$ extraction was up to about $8 \%$ higher for the extraction of molybdenum conducted from $10^{-2} \mathrm{M}$ $\mathrm{Mo}(\mathrm{VI})$ than for that conducted from $10^{-4} \mathrm{M} \mathrm{Mo}(\mathrm{VI})$. In order to obtain high percentage $\mathrm{Mo}(\mathrm{VI})$ extraction, microwave powers of 20 and $100 \mathrm{~W}$ have lead to high percentages $\mathrm{Mo}(\mathrm{VI})$ extraction for experiments conducted with $0.01 \mathrm{M}$ and $1 \mathrm{M} \mathrm{HCl}$ solutions respectively.

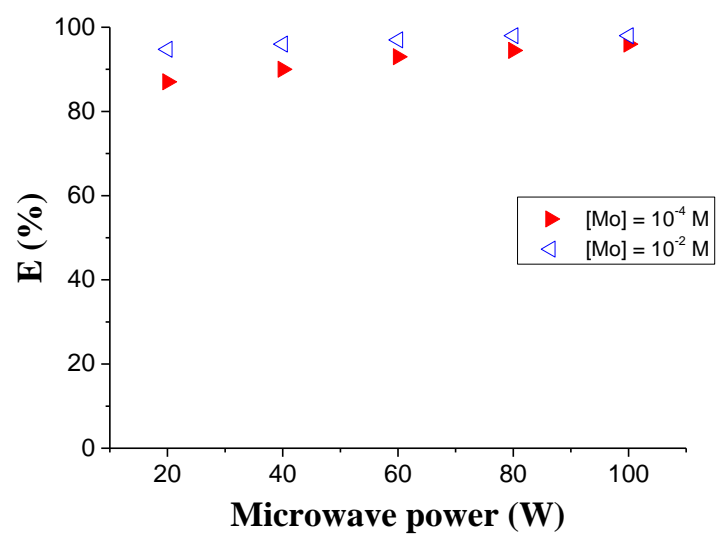

Figure 12. Percentage molybdenum extraction versus microwave power, $[\mathrm{HCl}]=1 \mathrm{M},[\mathrm{TOPO}]=0.02 \mathrm{M}, \mathrm{t}_{\text {irrad }}=10 \mathrm{~s}, \mathrm{~V}_{\mathrm{aqu}} / \mathrm{V}_{\text {org }}=1, \mathrm{~T}=26^{\circ} \mathrm{C}$.

\section{CONCLUSION}

Based on the data presented in this paper, it was observed that, MAE and conventional extraction methods may be successfully used to extract molybdenum from diluted aqueous acidic solutions with TOPO. The findings indicate that for both extraction techniques the percentage Mo(VI) extraction can be significantly improved by simply increasing one of the parameters the $\mathrm{HCl}$ concentration, molybdenum concentration, TOPO concentration or to a less extent microwave power. The MAE method showed obvious advantages in terms of short duration (10 s versus $15 \mathrm{~min}$ ) and significantly better percentage molybdenum extraction in comparison with conventional solvent extraction technique. The extent of percentage Mo(VI) extraction was close to $100 \%$ under certain operating conditions. Such promising results obtained also indicated that microwave-assisted extraction method is a very useful tool for the solvent extraction of molybdenum.

\section{ACKNOWLEDGEMENT}

The authors wish to thank the director of the Department of Analytical Chemistry, Nutrition and Food Sciences University of Alicante-Spain, Mr José-Luis Todoli, for his help in the realization of this work. 


\section{REFERENCES}

Banda, R., Sohn, S. H., \& Lee, M. S. (2012). Process development for the separation and recovery of Mo and Co from chloride leach liquors of petroleum refining catalyst by solvent extraction. Journal of Hazardous Materials, 213, 1-6.

Basualto, C., Marchese, J., Valenzuela, F., \& Acosta, A. (2003). Extraction of molybdenum by a supported liquid membrane method. Talanta, 59(5), 9991007.

Behera, S. S., Panda, S. K., Mandal, D., \& Parhi, P. K. (2019). Ultrasound and Microwave assisted leaching of neodymium from waste magnet using organic solvent. Hydrometallurgy, 185, 61-70.

Bonrath, W. (2004). Chemical reactions under "non-classical conditions", microwaves and ultrasound in the synthesis of vitamins. Ultrasonics Sonochemistry, 11, 1-4.

Boucherit, A., Khalaf, H., Paredes, E., \& Todoli, J. L. (2012). Development of a new aerosol phase extraction method for metal determination through inductively coupled plasma atomic emission spectrometry. Talanta, 99, 330-334.

Chaibou Yacouba, A. R., Laouali Ibrahim, S., \& Natatou, I. (2019). Comparative study of solvent extraction of molybdenum by various extractants. Turkish Journal of Chemistry, 43, 84-93.

Cid, B. P., Alborés, A. F., Gómez, E. F., \& López, E. F. (2001). Use of microwave single extractions for metal fractionation in sewage sludge samples. Analytica Chimica Acta, 431(2), 209-218.

Cyganowski, P., Cierlik, A., Leśniewicz, A., Pohl, P., \& Jermakowicz-Bartkowiak, D. (2019). Separation of $\operatorname{Re}(\mathrm{VII})$ from $\mathrm{Mo}(\mathrm{VI})$ by anion exchange resins synthesized using microwave heat. Hydrometallurgy, 185, 12-22.

Díez-Ortiz, M., Giska, I., Groot, M., Borgman, E. M., \& Van Gestel, C. A. M. (2010). Influence of soil properties on molybdenum uptake and eliminati on kineticsin the earthworm Eisenia Andrei. Chemosphere, 80, 1036-1043.

Filik, H., Tütem, E., \& Apak, R. (2004). Use of the molybdenum-thiocyanaterhodamine $6 \mathrm{G}$ ternary complex for spectrophotometric molybdenum determination without extraction. Analytica Chimica Acta, 505(1), 77-82.

Ghadiri, M., Ashrafizadeh, S. N., \& Taghizadeh, M. (2014). Study of molybdenum extraction by trioctylamine and tributylphosphate and stripping by ammonium solutions. Hydrometallurgy, 144-145, 151-155.

Gharehbaghi, M., \& Shemirani, F. (2011). Ionic liquid-based dispersive liquid-liquid microextraction and enhanced spectrophotometric determination of molybdenum (VI) in water and plant leaves samples by FO-LADS. Food and chemical toxicology, 49, 423-428.

Holzinger, S., Anke, M., Röhrig, B., \& Gonzales, D. (1998). Molybdenum intake of adults in Germany and Mexico. Analyst, 123, 447-450.

Huang, Y., Zhang, T. A., Dou, Z., Liu, J., \& Tian, J. (2016). Influence of microwave heating on the extractions of fluorine and Rare Earth elements from mixed rare earth concentrate. Hydrometallurgy, 162, 104-110.

Imam, D. M. \& El-Nadi, Y. A. (2018). Recovery of molybdenum from alkaline leach solution of spent hydrotreating catalyst by solvent extraction using methyl tricaprylammonium hydroxide. Hydrometallurgy, 180, 172-179.

Ivam Jr., M. V., Paulino, J. F., \& Afonso, J. C. (2008). Hydrometallurgical route to recover molybdenum, nickel, cobalt and aluminum from spent hydrotreating 
catalysts in sulphuric acid medium. Journal of Hazardous Materials, 160, 310317.

Li, Y., Lix, Z., Wang, B., Dong, Z., \& Song, S. (2019a). A fundamental study of leaching kinetics and mechanisms of molybdenite assisted by mechanical activation. Minerals Engineering, 131, 376-384.

Li, Z., Zhang, G., Zeng, L., Guan, W., Xiao, L., Li, Q., Cao, Z., \& Lu, X., (2019b). Continuous solvent extraction operations for the separation of $\mathrm{W}$ and Mo in high concentrations from ammonium solutions with acidified N1923. Hydrometallurgy, 184, 39-44.

López-García, I., Viňas, P., Romero-Romero, R., \& Hernández-Cŏrdoba, M. (2007). Liquid chromatography-electrothermal atomic absorption spectrometry for the separation and preconcentration of molybdenum in milk and infant formulas. Analytica Chimica Acta, 597(2), 187-194.

Mahandra, H., Singh, R., \& Gupta, B. (2018). Development of a hydrometallurgical route for the recovery of molybdenum from spent hydrodesulphurization catalyst using Cyphos IL 104. Journal of Industrial and Engineering Chemistry, 65, 213223.

Morreale, A. C., Novog, D. R., \& Luxat, J. C. (2012). A strategy for intensive production of molybdenum-99 isotope for nuclear medicine using CANDU reactors. Applied Radiation and Isotopes, 70(1), 20-34.

Nguyen, T. H., and Lee, M. S. (2015). Separation of molybdenum(VI) and tungsten(VI) from sulfate solutions by solvent extraction with LIX 63 and PC 88A. Hydrometallurgy, 155, 51-55.

Park, K. H., Reddy, B. R., Mohapatra, D., \& Nam, C. W. (2006). Hydrometallurgical processing and recovery of molybdenum trioxide from spent catalyst. International Journal Mineral Processing, 80, 261-265.

Pathak, S. K., Singh, S. K., Mahtele, A., \& Tripathi, S. C. (2010). Studies on extraction behaviour of molybdenum (VI) from acidic radioactive waste using 2(ethylhexyl) phosphonic acids, mono 2(ethylhexyl) ester (PC-88A)/ndodecane. Journal of Radioanalytical and Nuclear Chemistry, 284(3), 597-603.

Relić, D., Đorđević, D., Sakan, S., Anđelković, I., Pantelić, A., Stanković, A., \& Popović, R. (2013). Conventional, microwave, and ultrasound sequential extractions for the fractionation of metals in sediments within the Petrochemical Industry, Serbia. Environmental Monitoring and Assessement, 185(9), 76277645.

Remya, N., \& Lin, J. G. (2011). Current status of microwave application in wastewater treatment-A review. Chemical Engineering Journal, 166, 797-813.

Saberyan, K., Maragheh, M. G., Ashtari, P., \& Alamdari, S. K. (2003). Liquid-liquid extraction of molybdenum(VI) from acidic media with Cyanex-301. Minerals Engineering, 16, 391-393.

Sato, T., Watanabe, H., \& Suzuki, H. (1990). Liquid-liquid extraction of molybdenum(VI) from aqueous acid solutions by TBP and TOPO. Hydrometallurgy, 23(2-3), 297-308.

Thompson, L. H., \& Doraiswamy, L. K. (1999). Sonochemistry: science and engineering. Industrial and Engineering Chemistry Research, 38, 1215-1219. 
Tian, L., Xu, Z., Chen, L., Liu, Y., \& Zhang. T. A. (2019). Effect of microwave heating on the pressure leaching of vanadium from converter slag. Hydrometallurgy, $184,45-54$.

Van Gestel, C. A. M., Borgman, E., Verweij, R. A., \& Díez-Ortiz, M. (2011). The influence of soil properties on the toxicity of molybdenum to three species of soil invertebrates. Ecotoxicology and Environmental Safety, 74(1): 1-9.

Wang, M., Wang, X., and Liu, W. (2009). A novel technology of molybdenum extraction from low grade $\mathrm{Ni}-\mathrm{Mo}$ ore. Hydrometallurgy, 97, 126-130.

Wu, J., Wei, C., Li, X., Wang, S., Wang, M., and Li, C. (2012). Selective extraction of Mo using Cyanex-272 and tributyl phosphate from low grade Ni-Mo ore leach liquor. Separation and Purification Technololgy, 99, 120-126.

Xia, D. K., and Pickles, C. A. (1997). Applications of microwave energy in extractive metallurgy, a review", Technical Paper, Canadian Institute of Mining, Metallurgy and Petroleum. CIM Bulletin, 90(1011), 96-107.

Yamashoji, Y., Matsushita, T., \& Shono, T. I. (1986). Extraction of molybdenum(VI) by bis-dioctylphosphinyl)-alkanes. Polyhedron, 5(1), 1291-1295.

Zeid, M. M., Masry, B. A., Kassem, A. T., Noweir, H. G., Saad, E. A., \& Daoud, J. A. (2018). Extraction of molybdenum (VI) from nitric acid medium and its recovery from Gattar granite ore using CYANEX 923 in kerosene. Hydrometallurgy, 176, 139-146.

Zeng, L., \& Cheng, C. Y. (2009). A literature review of the recovery of molybdenum and vanadium from spent hydrodesulphurisation catalysts: Part I: Metallurgical processes. Hydrometallurgy, 98(1-2), 1-9. 